\title{
A meta-analysis of peer-assisted learning on examination performance in clinical knowledge and skills education
}

Yanrui Zhang ${ }^{1}$ and Mark Maconochie $2^{2^{*}}$

\begin{abstract}
Background: Peer-assisted learning is a method of active learning that is gaining traction throughout higher education. In the medical curriculum, peer-assisted learning has been the subject of independent studies collecting various types of data. However, an overall analysis of those studies providing objective measurements of the influence of peer-assisted learning could be particularly useful for teachers and students alike in a knowledge-heavy curriculum such as medicine. In this study we set out to analyse the efficacy of peer-assisted learning on medical students'learning of clinical knowledge and skills that is assessed through some objective examination, and thereby define whether such approaches have a reproducible benefit for inclusion in the medical curriculum.

Methods: Databases including Pubmed, Embase and Science Direct were searched for relevant studies containing randomized controlled trials (RCTs) of peer-assisted learning published before July 29th ,2020. A meta-analysis was performed by using RevMan 5.3 software.

Results: Thirteen studies involving 2,003 medical students were analyzed for clinical knowledge and skills gains that included some objective measurement of learning. The results of this meta-analysis indicated that considering all these studies together, peer-assisted learning leads to improvements in clinical knowledge and skills learning for medical students compared with traditional teacher-led passive learning. One study was found likely to be a source of significant heterogeneity, and when this was removed from the meta-analysis, the pooled effect was no longer statistically significant.

Conclusions: Peer-assisted learning can be an effective method of learning applied to medical student education. Active learning through peer-assisted learning should be seen as complementary to teacher-led approaches. Two of the individual studies on peer-assisted learning show a statistically significant benefit on examination performance compared to the other studies considered, that either show negligible benefits or at worst no detriment in learning. This highlights the need for more high-quality and focused randomized control trials to identify those critical parameters that lead to improved student learning using such approaches.
\end{abstract}

Keywords: Peer-assisted learning, Medical student education, Active learning, Clinical skills teaching

*Correspondence: mark.maconochie@qmul.ac.uk

${ }^{2}$ School of Biological and Chemical Sciences, Queen Mary University

of London, Mile End Road, E1 4NS London, UK

Full list of author information is available at the end of the article

\begin{abstract}
Background
Traditional lecture-based teaching is the predominant educational strategy widely used and praised by many teachers and students in higher education across the world [1, 2]. It was long considered to be the best route to directly transfer knowledge to students [3]. However, the
\end{abstract}

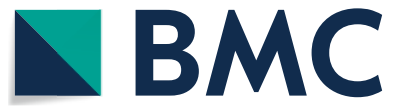

(c) The Author(s) 2022, corrected publication 2022. Open Access This article is licensed under a Creative Commons Attribution 4.0 International License, which permits use, sharing, adaptation, distribution and reproduction in any medium or format, as long as you give appropriate credit to the original author(s) and the source, provide a link to the Creative Commons licence, and indicate if changes were made. The images or other third party material in this article are included in the article's Creative Commons licence, unless indicated otherwise in a credit line to the material. If material is not included in the article's Creative Commons licence and your intended use is not permitted by statutory regulation or exceeds the permitted use, you will need to obtain permission directly from the copyright holder. To view a copy of this licence, visit http://creativecommons.org/licenses/by/4.0/. The Creative Commons Public Domain Dedication waiver (http://creativecommons.org/publicdomain/zero/1.0/) applies to the data made available in this article, unless otherwise stated in a credit line to the data. 
effectiveness of this approach is increasingly being questioned as this didactic teaching methodology is a passive, surface approach, that requires little commitment from students in their learning [4]. Further, it has been argued that the traditional lecture alone is inadequate and ineffective for current educational strategies, due to the passive nature and limit of students' interactions $[2,5,6]$. Didactic delivery aims to transmit knowledge to students without any feedback and minimal interaction. This teaching strategy rarely mobilizes students' initiative and is unable to inspire their creativity in the learning process. Traditional lectures thus tend to be relatively unsuccessful at initiating higher order thinking in students. This weakness has been exacerbated in recent years with the growth of the student population and concomitant class sizes, led by the demands of society worldwide to have a better educated workforce. An increase in class size leads to even fewer teacher-student classroom interactions [4].

Such passive learning strategies are in stark contrast to active learning, which is designed to stimulate student learning through performing tasks that directly engage them with knowledge acquisition and understanding. Furthermore, active learning arouses students' enthusiasm to learn, promotes interactions between students $[2,7]$ and reinforces student-teacher interactions. Much research proposes that active learning is far more effective than the traditional lecture for deeper student learning $[4,8-18]$. One active learning strategy is peer-assisted learning, defined as learning through matched-status individuals from "similar social groupings who are not professional teachers" [4, 9]. Topping [4] concluded that peer-assisted learning works particularly well when used alongside traditional lectures, and also is of benefit to the teacher as it allows for rapid feedback from students on their learning experience and depth.

However, whilst there is good evidence suggesting that peer-assisted learning is effective for students in general to develop life-long autonomous learning habits, most studies that look at the effectiveness of peer-assisted learning are qualitative. There are only a relatively small number of independent quantitative studies that provide objective statistical data and furthermore, few meta-analyses that attempt to quantitatively analyse the effect of peer-assisted learning. Balta [2] carried out a meta-analysis on peer-assisted learning across higher education that illustrated the positive effects on learning in addition to improvements in student achievement. Within the medical curriculum, a recent meta-analysis in 2020 [19] found significant effectiveness of peer-assisted learning, but this contrasts with an earlier meta-analysis in 2016 [20] that found no significant difference between peerled and faculty teaching. There are several studies that in general show the positive effects for students of peerassisted learning (for recent reviews see [12, 21]), where performance across a range of subjects in the medical curriculum have been examined to give an overall picture of the benefits. However, it is possible that peer-assisted learning may prove more beneficial in some specific subject areas in the medical curriculum. Given the potential for peer-assisted learning to be particularly beneficial to medical students, and the differing conclusions of previous, more general meta-analyses, this study was initiated to carry out a meta-analysis to systematically analyse the use of peer-assisted learning in clinical skills and knowledge teaching and learning. The meta-analysis is focussed on those studies where learning outcomes are objectively measured by some form of examination, given the importance of assessments as a driver to student learning.

\section{Methods}

\section{Search strategy}

A systematic search of the published literature was performed using Pubmed, Embase and Science Direct databases up to July 29th, 2020. Search terms used in literature searching were ("peer assisted learning" OR "PAL" OR "peer learn" OR "peer tutor" OR "peer teach") AND ("traditional teaching" OR "faculty" OR "expert" OR "instructor" OR "staff" OR "tutor"). The specific search term "medical" was not used to ensure a sufficient pool of studies was recovered to apply the study selection procedure documented below.

\section{Study selection}

The selection of research studies was performed following the PRISMA statement [22]. Studies were selected for inclusion in this meta-analysis only when they met the specific inclusion criteria detailed below. A hierarchical literature screen was carried out first through analysing article titles and excluding obviously irrelevant publications, and further delimited through deeper scrutiny of abstracts and the full text to identify papers in the appropriate subject area. All potentially eligible papers were retrieved and examined in full without bias to their conclusions in being selected. The aim of the database search and study selection procedure was to collect randomized-controlled trials of medical students receiving peer-assisted learning and traditional teacher-led learning in clinical skills and knowledge subjects.

Inclusion criteria for papers considered in the metaanalysis: (1) Study type: Randomized Controlled Trial; (2) Population: Medical students. (There was no limit on gender, age, race and nationality); (3) Intervention: the experimental group used peer-assisted learning to teach students, the control group used traditional teacherled learning. Note that peer-assisted learning should 
conform to the definition given by Topping of "the acquisition of knowledge and skill through active helping and supporting among status equal or matched companions" [23]. Cooperative learning and peer-mentoring terms were not included; (4) Outcomes: clinical knowledge and clinical skills gain was measured by some form of objective examination after the intervention to assess whether the intervention led to any change in assessed learning outcome. Only randomised controlled trials were used in the meta-analysis as these provide the highest quality of evidence with quantitative outputs.

Exclusion criteria: (1) The reports were not available in English; (2). Studies with incomplete data sets; (3) Duplicate studies arising from different database searches; (4) Studies that consisted of subjective measurements of learning only such as student questionnaires, focus groups etc. Although these studies were excluded from the meta-analysis, some were used to provide useful and important commentary in the discussion.

\section{Data extraction and quality assessment}

The following key information was collated during data extraction: basic information of the reported research, for instance, details of the first author, nature of intervention, academic level of student and peer-tutor, and nature/level of control teacher, type of objective assessments used and intervention subject area, whether any peer-training and its nature was offered, and whether the study reported any statistical support of the findings. The quality of the individual studies included in this metaanalysis was assessed according to Cochrane Collaboration's tool for assessing risk of bias [24, 25].

\section{Statistical analysis}

Statistical analysis was performed to minimize the risk of bias using RevMan 5.3 software. Parametric variables were presented as mean \pm standard deviation (SD). The outcome of continuous variables used standardized mean difference (SMD) of exam scores with 95\% confidence intervals (CIs) as the effect size. The level of significance for the meta-analysis was set as $\alpha=0.05$, i.e., a probability of $P<0.05$ was judged statistically significant. Heterogeneity among the results from the different studies was detected by using the chi-square test $(\alpha=0.1)$ together with calculating the $I^{2}$ statistic. The $I^{2}$ value gives an indication of the level of variation due to heterogeneity rather than due to chance [26]. $I^{2}$ was calculated using the formula $I^{2}=(\mathrm{Q}-\mathrm{df}) / \mathrm{Q} \times 100 \%$, where $\mathrm{Q}$ is the Cochran heterogeneity statistic and $\mathrm{df}$ the degrees of freedom, equivalent to the number of studies included in the metaanalysis minus one. A value of $I^{2}$ greater than $50 \%$ represents high heterogeneity amongst the data, and a value below $50 \%$ low or moderate heterogeneity $[24,26]$.
To analyse heterogeneity between studies, an influence analysis was carried out using the metaninf method. As this meta-analysis demonstrated a statistically significant level of heterogeneity (formally $>50 \%$ represents substantial heterogeneity), a random-effect model for the meta-analysis was used. Cochrane collaboration's tool was used to analyse the risk of bias of this meta-analysis. Revman was used to produce a risk assessment summary for the overall study group as well as to investigate the risk of bias for the individual studies. Further analysis of bias was investigated using a funnel plot to investigate publication bias. In order to test for significance for publication bias, the Egger test and the Begg test were used. However, funnel plots have come under criticism for gauging publication bias only [27] so other possible sources of asymmetry were considered. Finally a forest plot was drawn using 95\% confidence limits under the random-effect model to summarise and conclude this study.

\section{Results}

\section{Delimiting appropriate studies for meta-analysis}

This analysis is focused on investigating whether studies on peer-assisted learning show any consistent improvement in learning achievement of clinical skills and knowledge as measured by examination(s). Searching of the relevant databases, Pubmed, Embase and Science Direct, revealed numerous studies that have investigated the possible effects of peer-assisted learning. However, we wished to focus on those conducted in medical schools. Using a hierarchical search strategy, we identified peerassisted learning studies using some form of randomized control trial. This initial screen yielded just over 9000 publications related to peer-assisted learning. Next, PRISMA protocols were used to further delimit those reports that adhered to a minimal set of reporting criteria to make them suitable for this meta-analysis and combined this with a risk of bias assessment as provided by Cochrane collaboration's tool. An overview of the selection protocol to identify sufficiently robust, controlled and focused reports relevant to the aim of this study is provided in Fig. 1.

\section{Analysis of risks with selected studies}

Thirteen studies were included for the meta-analysis [28-40] comprising a total sample size of $n=2,003 \mathrm{stu}-$ dents. The nature and characteristics of the individual peer-assisted learning studies chosen is summarized in Table 1 , and as demonstrated in this table, these originate from different areas of the clinical skills curriculum.

A risk analysis was subsequently carried out on the group of selected studies using Cochrane collaboration's tool and is represented graphically in Fig. 2. This analysis indicated there was a low risk of reporting, detection and 


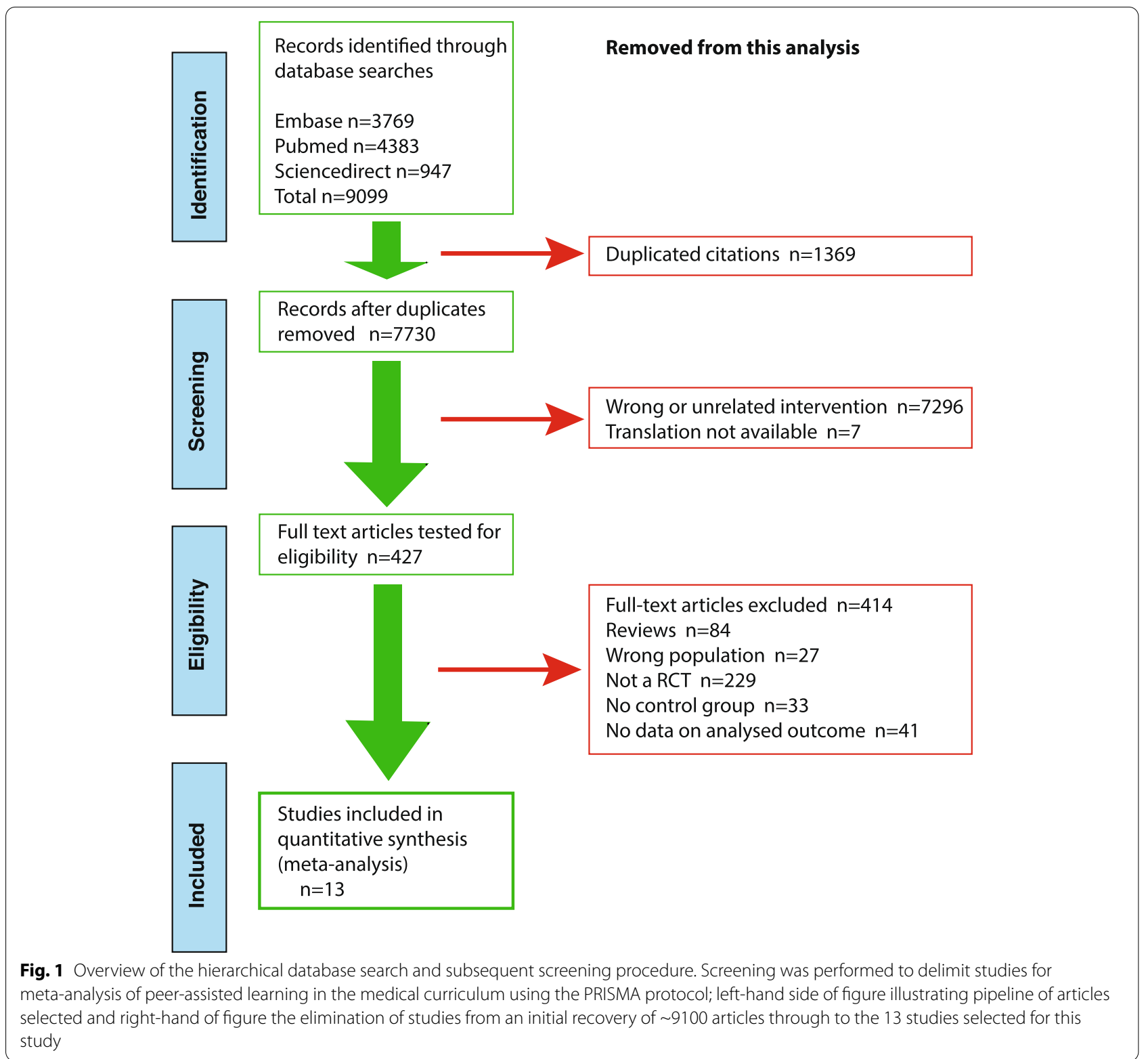

selection biases (Fig. 2). Only minimal levels $(<20 \%)$ of high-risk bias was suggested from performance and attrition categories, although we note there were also varying levels of unclear risk of bias for all risk categories (Fig. 2). However, from the level of risk that was categorised using this tool, these studies used together appear to carry a relatively low risk of bias. Risk assessment of bias for the individual studies indicated only $3 / 13$ studies showed a high level of risk bias in any category (Fig. 3), and the randomized controlled trials chosen were therefore judged to be of moderate to high quality. Whilst funnel plots have come under criticism for gauging publication bias only [27], visual inspection of the funnel plot comparing the standard error as a measure of study precision revealed asymmetry (Fig. 4). Tests for asymmetry in funnel plots are of low power, and since substantial heterogeneity was detected in this study, the number of studies required would need to be appreciably greater than the minimum recommended number of 10 studies [27] to be reliable. But although this meta-analysis only slightly exceeds this number, we performed two tests for publication bias. The Egger test was not significant for publication bias $(P$ $=0.249)$, whereas the Begg test was $(P=0.033)$. However, when the number of studies is low, the efficiency and reliability of the Egger test using linear regression is believed to be more powerful than the Begg method, that 


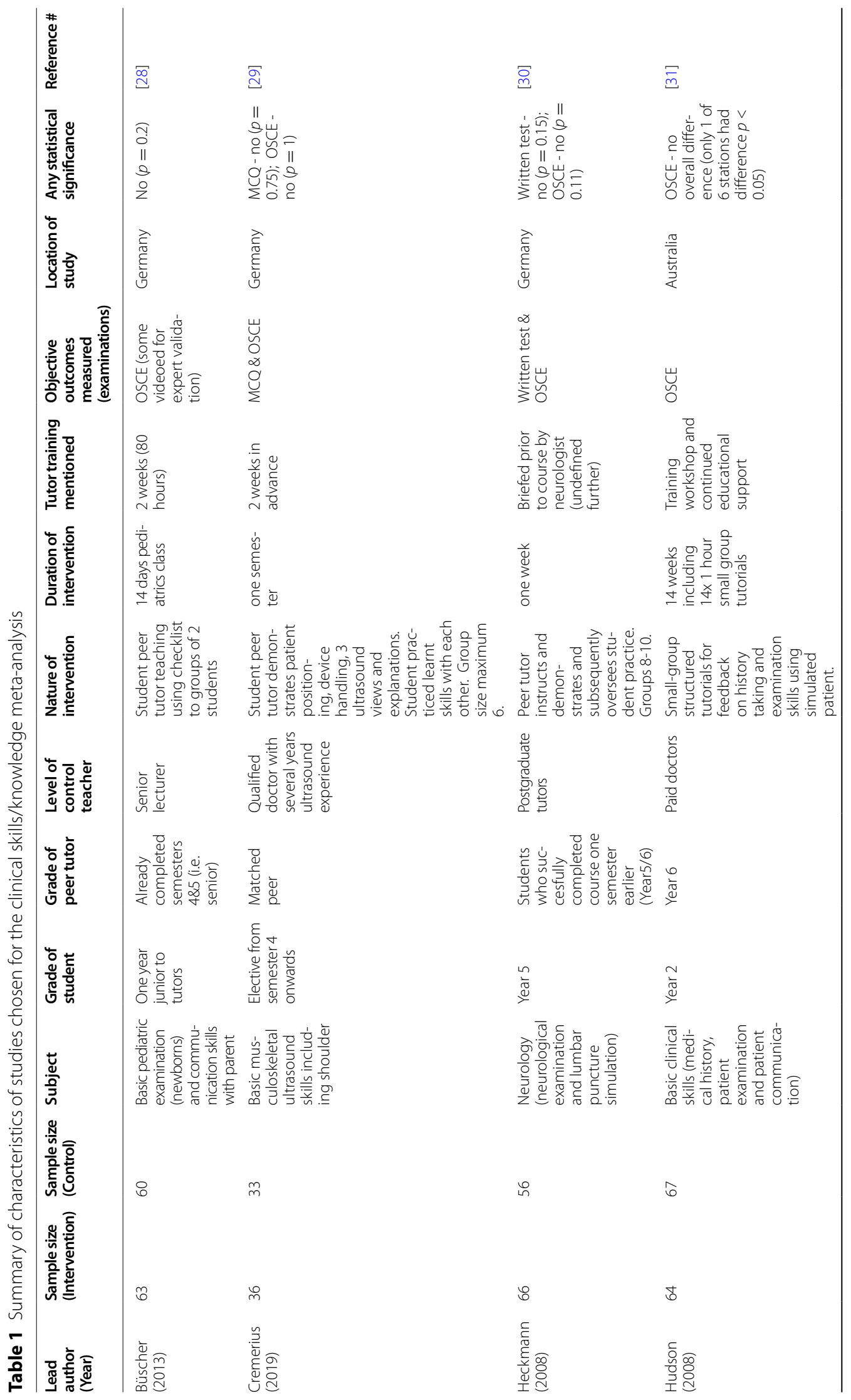




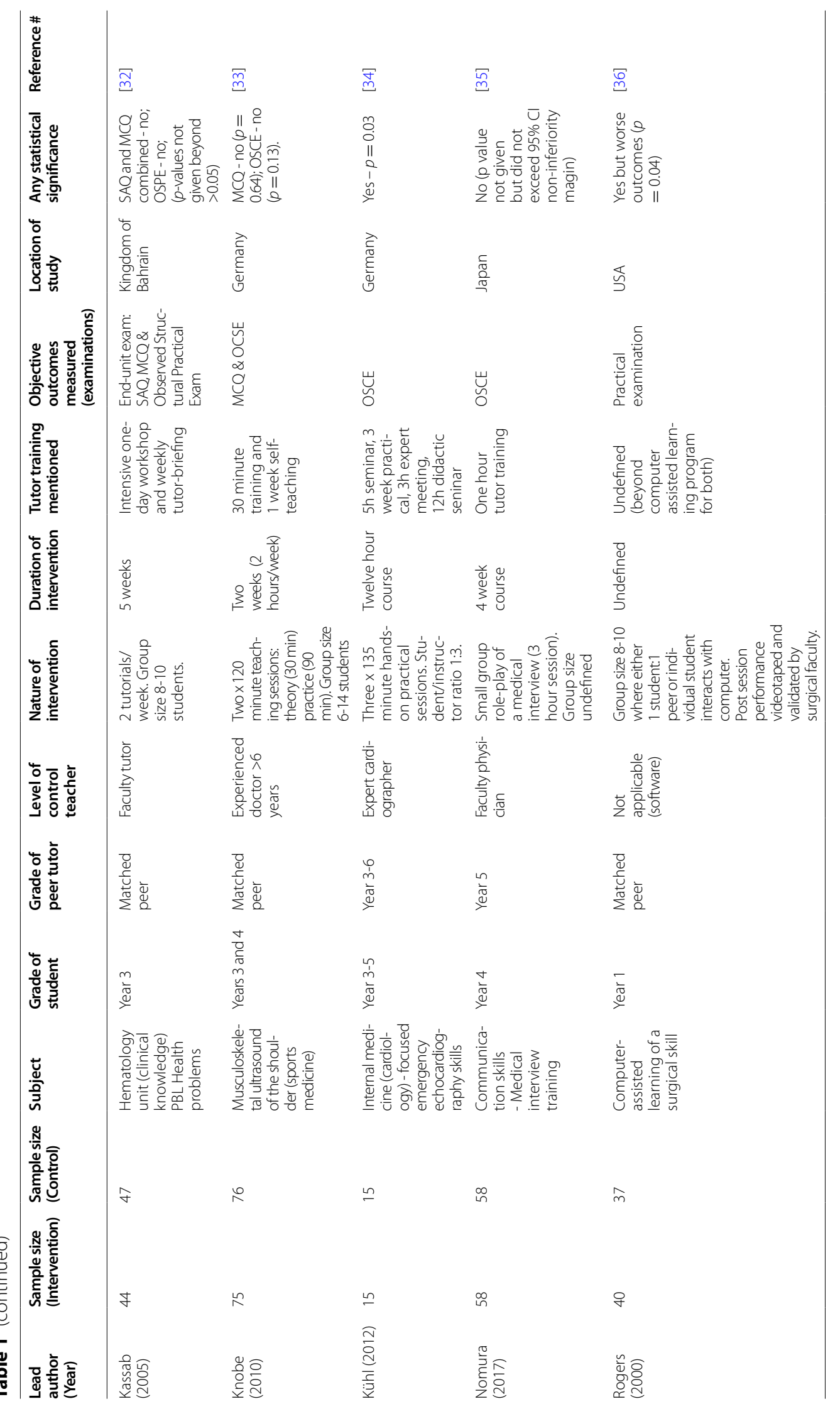




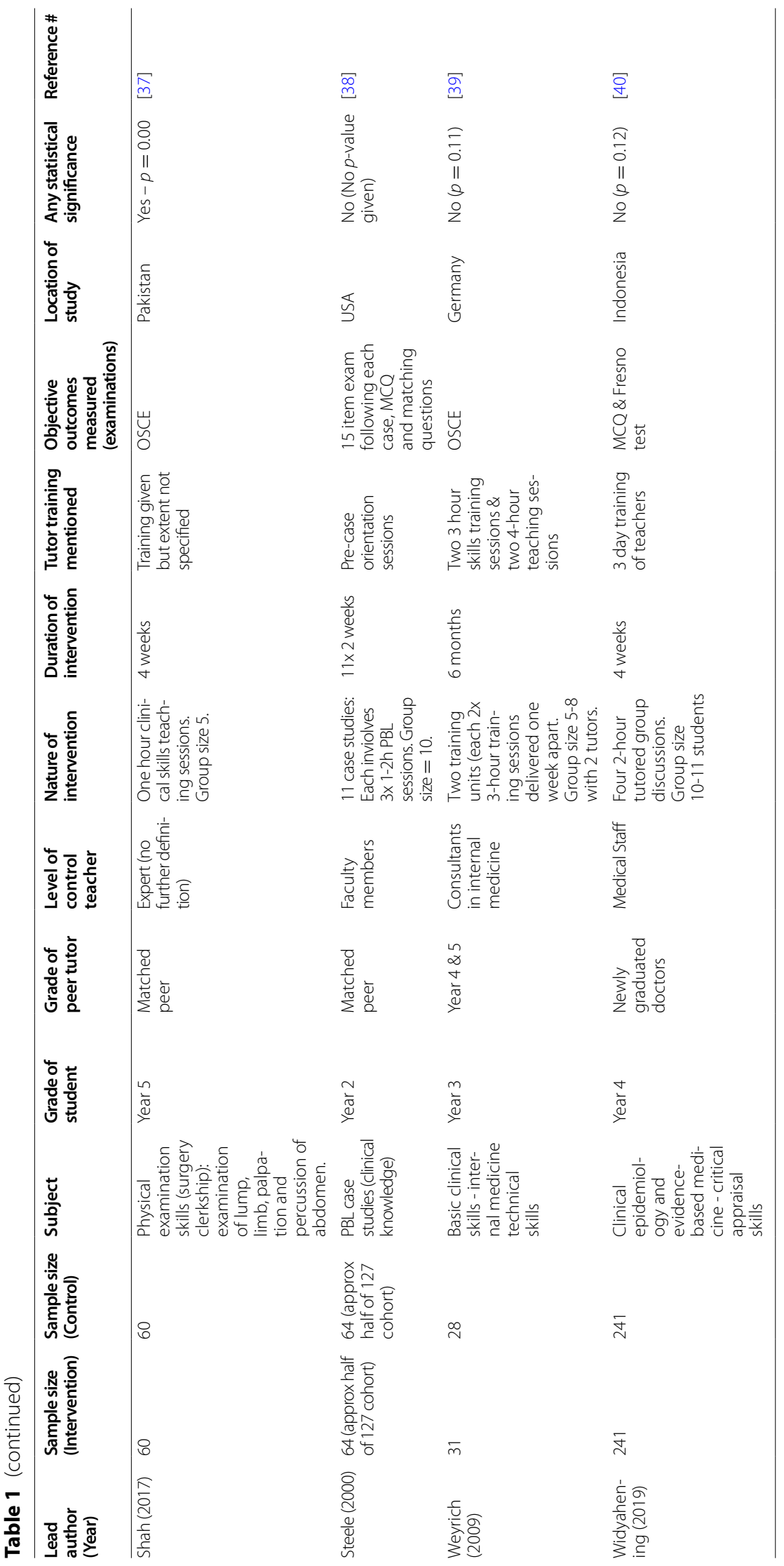




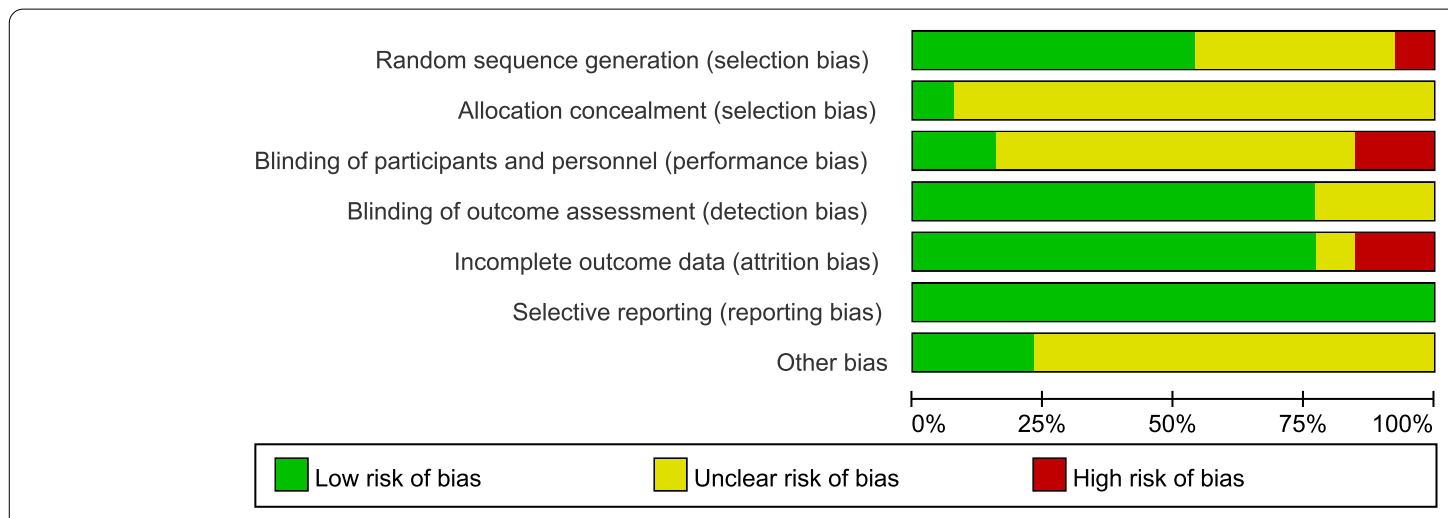

Fig. 2 Risk assessment for bias for the overall group of studies selected. Risk was assessed according to Cochrane collaboration's tool

uses rank correlation, and has very low power to detect biases for small sample sizes [41]. The asymmetry in the funnel plot could therefore suggest some reporting bias, which may be explained by studies that show less favourable effects not being published, compared to studies that do show favourable effects being more likely to be both written up and accepted for publication. There are several other possible explanations in addition to reporting bias that can lead to funnel plot asymmetry, such as heterogeneity, methodological quality and chance. Using the random effect model, if heterogeneity was large the plot would appear cylindrical [27] which it does not (Fig. 4). To analyse heterogeneity further an influence analysis was carried out. Between-study heterogeneity was examined where pooled estimates were calculated repeatedly, but omitting one study in each successive calculation (Fig. 5). This revealed that one study (Shah, 2017, [37]) had a very high effect size and was a clear outlier, and the overall effect size of pooled studies is smallest when this study is removed. Thus this study may be the main source of heterogeneity and distort the effect size estimate. The methodology used in studies could also lead to asymmetry, but in the selected studies, all appeared well set up and statistically analysed. Finally, the role of chance in leading to the observed plot asymmetry cannot be ruled out given the relatively small number of studies and the heterogeneity detected. However, taking into account the above caveats, this asymmetry could also indicate that the intervention of peer-assisted learning is indeed having a positive effect on objectively assessed learning outcomes.

\section{Meta-analysis of the selected studies}

The meta-analysis investigating whether treatment (peer-assisted learning) leads to any difference compared to controls is graphically presented as the forest plot in Fig. 6, either including (Fig. 6A) or excluding (Fig. 6B) the Shah (2017) study. Considering all 13 studies together (Fig. 6A), the meta-analysis indicated that medical students using peer-assisted learning showed an enhanced examination performance compared with traditional teacher-led learning overall. This result is statistically significant $(P=0.03)$ with significantly high heterogeneity $\left(I^{2}=92 \%\right)$. The Shah study was shown to be a significant outlier above, therefore the forest plot was recalculated omitting this study since it is particularly influential as one of only three individual studies showing statistically significant improvement in assessed outcomes of peer-assisted learning (Fig. 6A). Removing this study from the meta-analysis reduces heterogeneity of the analysis $\left(I^{2}=77 \%\right)$, but the overall effect of the interventions no longer remains statistically significant $(P=0.12)$ (Fig. 6B). The forest plot illustrates that analysis of the 12 pooled studies showed there is no detriment to assessed outcomes from peerassessed learning (Fig. 6B). Thus peer-assisted learning is not inferior to teacher-led learning. However, there is no longer a statistically significant improvement in the assessed outcomes considering the pooled studies. Further, individually, only two of the 12 studies show improvement of assessed outcomes at a statistically significant level (Fig. 6B).

\section{Discussion \\ Meta-analysis of peer-assisted learning in clinical skills and knowledge}

This analysis of the pooled effect of peer-assisted learning compared to teacher-led learning in a set of clinical skills and knowledge subjects revealed there was no detriment to examination performance as an objective measure of learning outcome. For two of the clinical subjects, the haematology unit (clinical knowledge) and emergency echocardiography (skills), the improvement of peer-assisted learning over teacher-led learning was statistically significant $(95 \% \mathrm{CL})$. Considering the other 


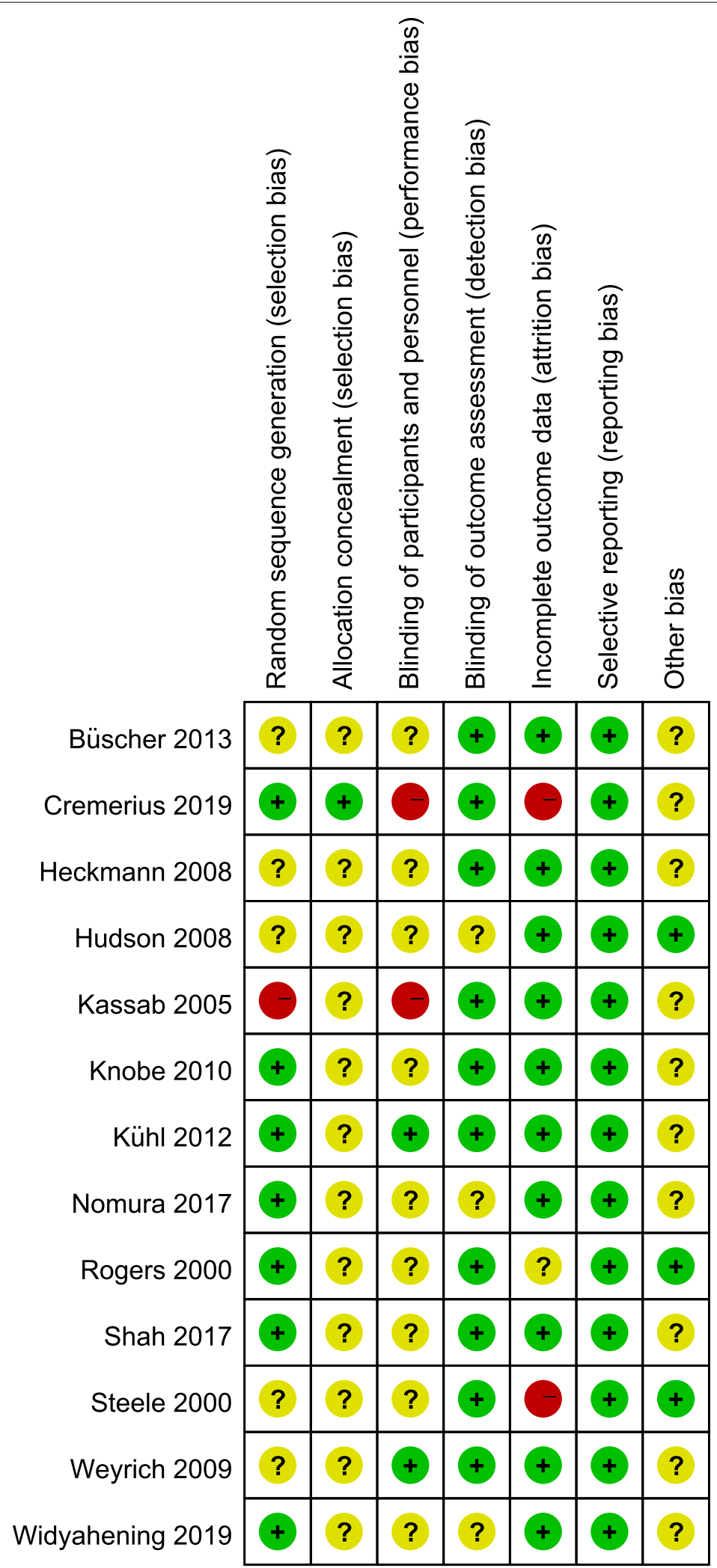

Fig. 3 Risk of bias summary for the individual studies assessed. Risk was assessed according to

Cochrane collaboration's tool for assessing risk of bias; colours representing levels of bias are as indicated in Fig. 2 


\section{Funnel plot with pseudo $95 \%$ confidence limits}

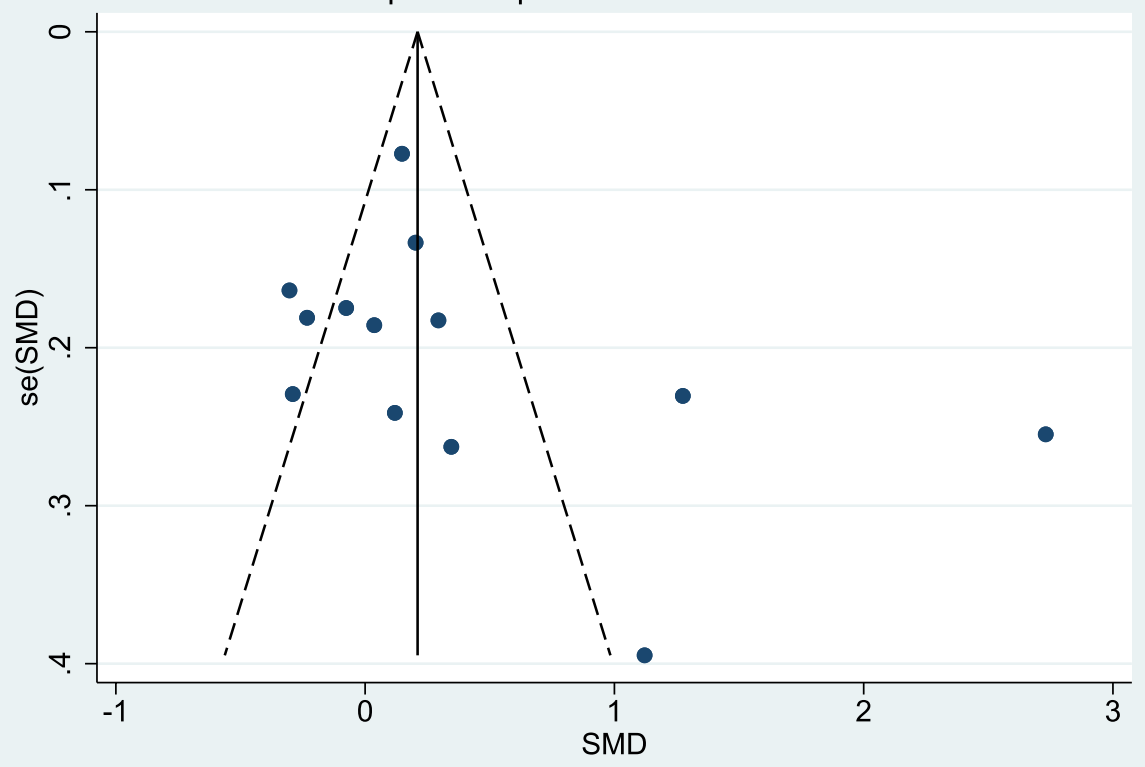

Fig. 4 Funnel plot to investigate publication bias. Standard error was used as method to quantify study precision. Each dot represents a specific study; the $y$-axis represents study precision (SE-standard error) and the x-axis shows the study's result (SMD- standardized mean difference)

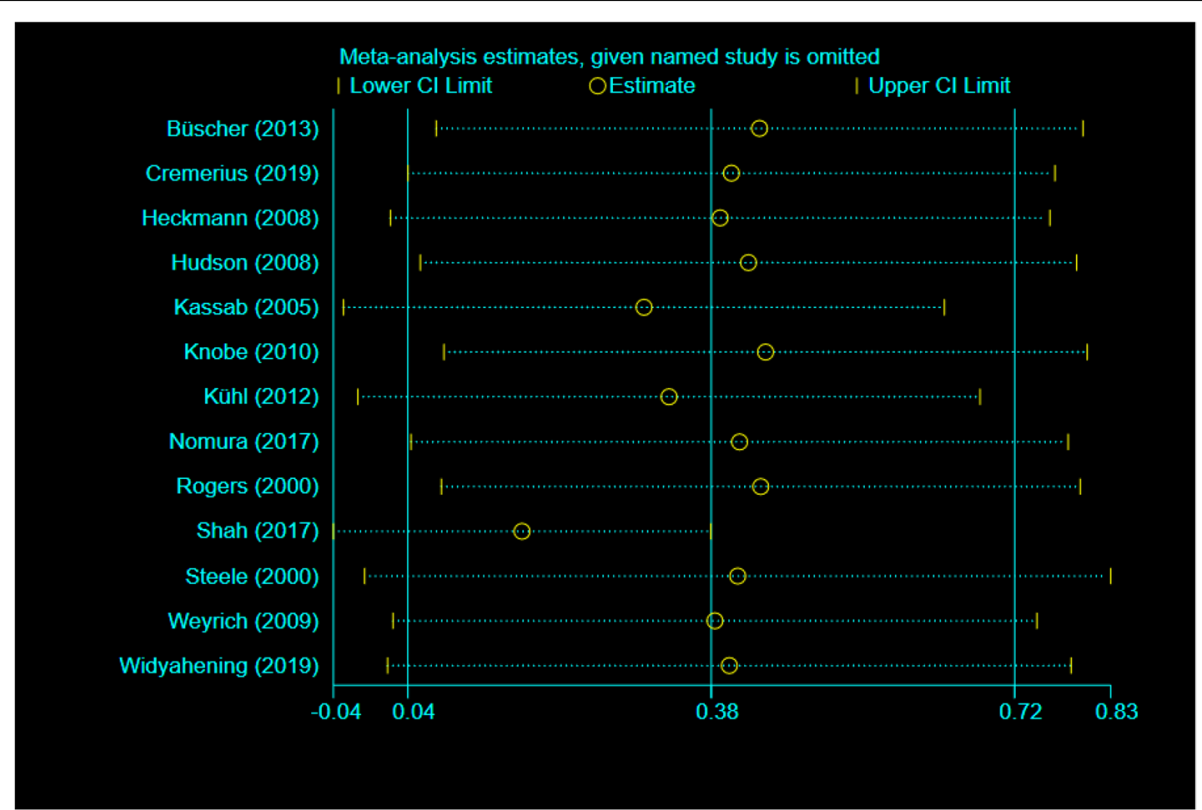

Fig. 5 Between-study heterogeneity analysed by influence analysis. Influence analysis was carried out by using metaninf to investigate the influence of each individual study on the overall meta-analysis summary. The horizontal axis indicates the overall standard mean difference and the two vertical lines each end indicate $95 \% \mathrm{CL}$. Circles indicate the pooled effect calculation when the study as indicated on the left is omitted. This demonstrates the Shah (2017) study as an outlier 


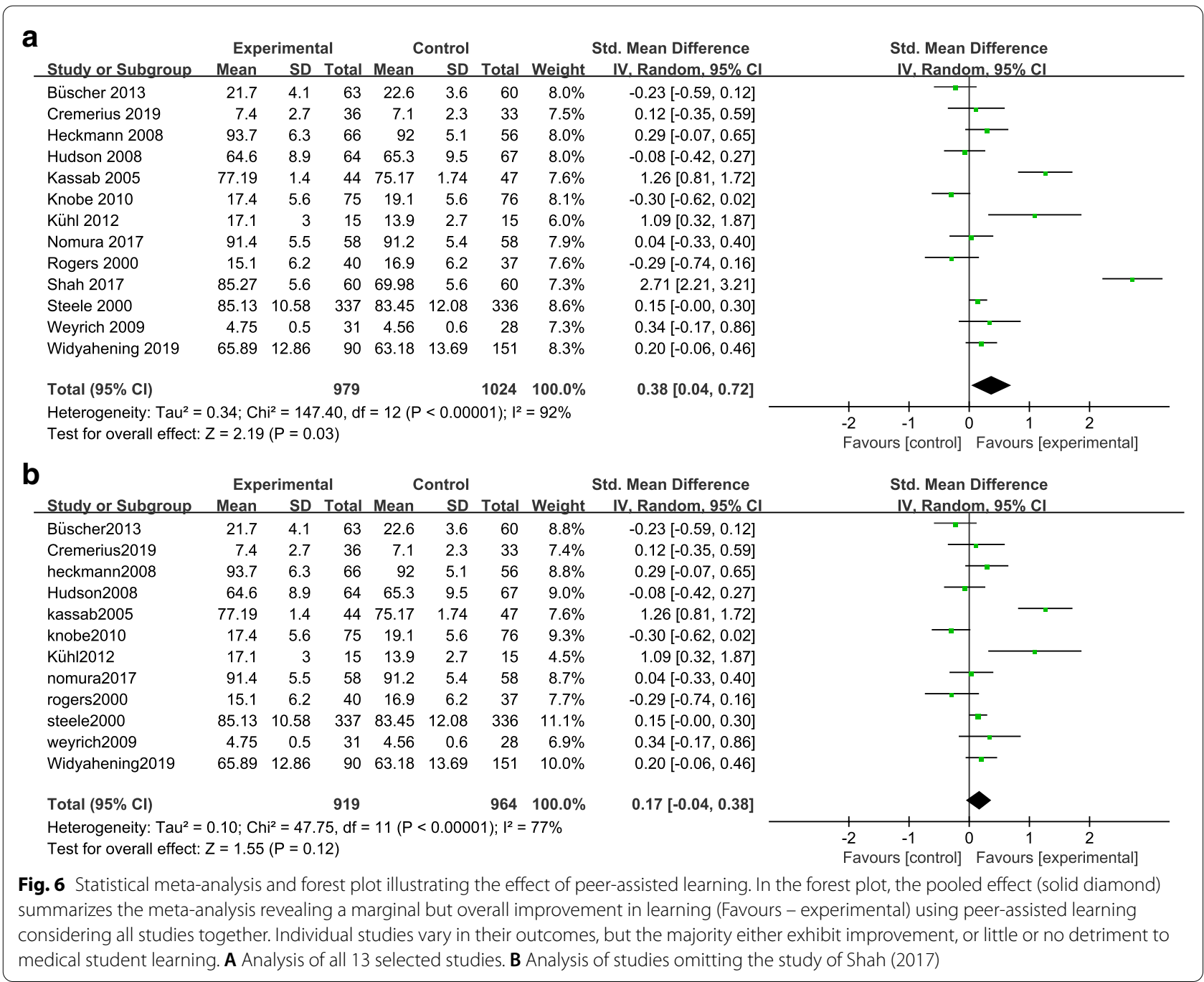

individual studies however, there was no statistically significant enhancement of assessed learning outcome, although as for the pooled effects, peer-assisted learning was not detrimental, an important finding as class sizes become larger as the demand for more trained doctors increases. This analysis therefore supports the notion that peer-assisted learning in clinical skills is a useful form of active experiential learning, and furthermore, can enrich the student experience by providing additional variety in teaching and learning modes to accommodate the different learning preferences that students bring.

Are there any commonalities between the two studies [32, 34] that show statistically significant improvement that may explain why these studies appear to offer enhanced learning outcomes? The specific subject matter does not appear critical as they come from different areas of clinical skills and knowledge training. Also, the academic level of the peer-tutor varies involving either horizontal learning, learning from fellow student peers at the same educational level, or vertical learning involving student peer tutors at nearby but more advanced academic levels. In both studies peer-tutor training was provided, albeit to differing extents, but this is also true of studies that were found not to exhibit statistically significant improvement in assessed learning outcome. The parameter that may influence the success of peer-assisted learning is the academic level of student learners from at least year 3. By year 3, students should have developed better educational maturity in a higher education setting that involves less didactic teaching and have become more receptive to learn from their peers and near-peers. However, better educational maturity is likely to be only one contributory factor in addition to student and student-tutor motivation, complexity of subject matter, effectiveness of tutor-training and factors that are discussed below. It is worth bearing in mind that one study (Shah et al.) was identified as a possible cause of heterogeneity. When eliminated from the final meta-analysis, the overall meta-analysis no longer 
showed a statistically significant improvement in assessed outcome but did indicate no detriment to learning. This warns against over-interpretation of individual studies. Nevertheless, the statistical exclusion of just one from 13 studies indicates there is merit in considering the mechanisms involved, advantages and disadvantages of incorportating peer-assisted learning in the medical curriculum.

\section{How peer-assisted learning may contribute to learning}

Ten Cate and Durning [42] put forward the cognitive congruence hypothesis to describe how peer-assisted learning can have a positive impact when studying with peers of a similar educational level. Knowledge gaps amongst peers may be better understood than in teacherdirected learning as there is a similar level of baseline knowledge. This is in contrast with teacher-led learning, where the teacher may make incorrect assumptions concerning existing knowledge of fundamental concepts, particularly when teaching elements at a higher educational level where these concepts are critical for understanding. This knowledge gap could influence the motivation of students to learn.

The cognitive congruence hypothesis suggests that in a peer-peer learning community, students will be more open and less guarded when they get along with their peers. However, this indicates that the relationship between students also affects the group learning state. This could create inequalities in the effectiveness of peer-assisted learning. Differences in individual students' study habits and their social competence can also impact on them being receptive and open to learning from peers, and gender biases may also influence peer-assisted learning [43].

\section{Student concerns with peer-assisted learning}

Students involved in peer-assisted learning retain concerns about the depth of knowledge and clinical experience of the peer-tutor to answer technically complex questions [11], and that peer tutors cannot compete with professional teachers with better pedagogical skills. Further, student ideology may be influenced by the reality of paying for a "traditional" medical education, and the negative perception engendered by receiving that education from fellow students. However, learning achievements with peer-tutors and professional teachers appear comparable when learning straightforward elements of knowledge, but the value of teacher-led learning appears to increase alongside the difficulty of the subject [38]. Since students worry about making mistakes in their learning that are not identified by their peers, it was suggested that esoteric and complex content is best taught by professional teachers and experts [38]. This meta-analysis and others across higher education provide evidence of the gains in student learning and should help counteract the variety of student concerns.

\section{Benefits of peer-assisted learning}

Peer-assisted learning serves as an important form of active learning that can improve knowledge retention and metacognitive awareness. During peer-assisted learning, students are less fearful of making errors in front of their peers rather than faculty, and therefore will have more opportunities to identify their defects and correct them before examinations and qualification. This promotes the development of clinical skills, where continued practice is effective in building and honing basic skills.

Students also have different learning preferences that relate to their individual strengths and weaknesses within different learning styles [44], and although learning styles and their use in educational strategies has attracted some criticism (reviewed in [45]), it is undoubtedly the case that students' learning abilities and strategies are not homogenous. We would argue that any educational strategy that adopts a variety of teaching methods is likely to benefit and be more inclusive to a wider proportion of the student cohort. It is not envisaged that peer-assisted learning would replace teacher-led learning, but rather that when used as a supplementary tool in the appropriate context, it has excellent potential to complement traditional teacher-led activities in the curriculum [10].

There are additional benefits of peer-assisted learning for the peer tutor. Peer-assisted learning is a bidirectional, reciprocal process, where mutual benefit is at the core $[9,46,47]$, and as any educator discovers when they first begin teaching, it is only when you attempt to explain to others that you fundamentally appreciate the level of your own understanding. This interplay between students as peer-learner and peer-tutor creates a more comfortable and less hierarchical teaching environment, making learning easier and more readily accessible $[11,30,31,35$, 47] and helps towards building students' confidence [11, $14,16,31,32,35,40,48]$. Since academic goals are shared in this collaborative learning effort, this promotes deeper learning and reduces stress during the learning process [30,38], where students are more engaged and can have greater ownership over their knowledge acquisition.

\section{The case for peer-assisted learning in the medical curriculum}

Medical students are a unique group within higher education as early in the medical curriculum, students are required to acquire a vast volume of fundamental theoretical knowledge that later aligns to varying degrees with its application to clinical practice. This overwhelming amount of knowledge unfortunately encourages memorization as a learning strategy for many students, leaving little room for deeper understanding and higher order thinking, ultimately leading to superficial learning. However, as the medical curriculum progresses, a 
stronger link of theoretical knowledge with application emerges, as students are exposed to clinical practice including hospital rotations and primary care. Strong "hands-on" skills are developed as well as the translation of theory into practice, and at this later stage, rote learning following didactic teaching approaches is insufficient to provide the knowledge required.

In medical school curricula in many countries, an ability to effectively communicate with others, from patients and their families through to other health care professionals is seen as an important competency [40]. Peer-teaching allows students to develop their conversational skills in a safe environment that will improve their communication competency [40].

Thus compared with traditional lectures, peerassisted learning would seem to be much more aligned with medical students' needs of applying theory and practice through active learning, "doing" rather than memorizing. Beyond the obvious benefits of learning per se, peer-assisted learning builds up self-confidence and collaborative skills for learning, and the ability to teach, lead and listen within a team. Together these skills will become important attributes for the student in future clinical practice.

\section{Strengths and limitations}

This study used meta-analysis protocols to generate a more accurate estimate of the effect of peer-assisted learning by analysing pooled studies rather than any one individual study alone [49]. Literature included in this study were all randomized controlled trials and variants of these such as randomized crossover studies, providing individual studies of high-quality, and their use of blinding (Figs. 2 and 3) helps reduce bias in the overall result.

This meta-analysis was limited to English-language publications, and qualitative research and grey literature were excluded. Furthermore, some heterogeneity was demonstrated in this meta-analysis and discussed above. It is not possible to conclude that peer-assisted learning is always "better" or more "successful" than traditional teacher-led activities. Instead, the meta-analysis is sufficiently robust to suggest that peer-assisted learning is an effective tool for targeted use in the medical curriculum in clinical skills learning with an effect that can be at least comparable, and sometimes an improvement, to traditional teacherled learning.

An uncontrolled factor in studies of peer-assisted learning is likely to be the quality, training and motivation of peer tutors, factors that are likely to vary from tutor to tutor and institution to institution. Whilst difficult to control, addressing inequality in individual peer-tutor ability and motivation is likely to be key to the successful use of peer-assisted learning. In addition, students need to "buy in" to peerassisted learning for this approach to be successful.

\section{Conclusions}

This study demonstrated that peer-assisted learning is not detrimental to student learning as assessed by examination performance compared with teacherled learning. Thus peer-assisted learning can aid in the development of a useful community of learning in clinical skills and clinical knowledge, with the caveats of ensuring the appropriate level of complexity in the learning task, and the appropriate training of peer tutors. However further studies into peer-assisted learning are required. For example, since peer-assisted learning can improve assessment performance in medical students' clinical skills and knowledge education in some cases, the parameters that lead to this remain unresolved but could be addressed through more highquality and focused randomized control trials.

\section{Acknowledgements}

We wish to thank Professor Zhijun Luo, director of the Joint Programme in Biomedical Sciences and Clinical Medicine at Nanchang University for support and encouragement of this study. We also wish to thank the BMC reviewers for many constructive comments on how to improve the manuscript.

\section{Authors' contributions}

$\mathrm{YZ}$ carried out the analysis; $\mathrm{YZ}$ and $\mathrm{MM}$ together discussed the findings and interpretation and prepared the manuscript. The author(s) read and approved the final manuscript.

\section{Funding}

This work was supported by the Jiangxi Province Education Reform Grant (JXJG-15-1-7),

\section{Availability of data and materials}

The individual datasets were taken from the publications cited in Table 1, and the data generated and analysed included in this article.

\section{Declarations}

Ethics approval and consent to participate

Not applicable as this is a statistical analysis on previously published reports.

Competing interests

The authors declare that they have no competing interests.

\section{Author details}

${ }^{1}$ Nanchang University Queen Mary School, Nanchang University, Room 215 Admin Building No. 1299 Xuefu Street, 330031 Nanchang, China. ${ }^{2}$ School of Biological and Chemical Sciences, Queen Mary University of London, Mile End Road, E1 4NS London, UK.

Received: 17 March 2021 Accepted: 14 February 2022 Published online: 5 March 2022

\section{References}

1. Cooper J, Robinson P. The argument for making classes smaller. New Directions for Teaching and Learning. 2000;2000:17-24.

2. Balta N, Michinov N, Balyimez S, Ayaz M. A meta-analysis of the effect of Peer Instruction on learning gain: Identification of informational and cultural moderators. Int J Educ Res. 2017;86:66-77. 
3. Simpson V, Oliver M. Electronic voting systems for lectures then and now: A comparison of research and practice. Australasian J Educ Tech. 2007;23:187208. https://ajet.org.au/index.php/AJET/article/view/1264/637.

4. Topping KJ. The effectiveness of peer tutoring in further and higher education: A typology and review of the literature. Higher Education. 1996; 32:321-345.

5. Lujan HL, DiCarlo SE. Too much teaching, not enough learning: what is the solution? Adv Physiol Educ. 2006; 30:17-22.

6. Knight JK, Wood WB. Teaching more by lecturing less. Cell Biol Educ. 2005; 4:298-310.

7. Biggs J. Enhancing Teaching through Constructive Alignment. High Educ. $1996 ; 32: 347-364$

8. Wareing $M$, Green $H$, Burden B, Burns $S$, Beckwith MA, Mhlanga F et al. "Coaching and Peer-Assisted Learning" (C-PAL) - The mental health nursing student experience: A qualitative evaluation. J Psychiatr Ment Health Nurs. 2018; 25:486-495.

9. Topping K, Ehly SE: Peer-assisted Learning, 1st edn: Routledge; 1998.

10. Taheri M, Amini M, Delavari S, Bazrafkan L, MazidiMoradi J. Effect of Peer Assisted Learning (PAL) education on knowledge, attitude and behavior related to prevention and control of diabetes. BMC Res Notes. 2019; 12:227.

11. Robinson Z, Hazelgrove-Planel E, Edwards Z, Siassakos D. Peer-assisted learning: a planning and implementation framework. Guide supplement 30.7--practical application. Med Teach. 2010; 32:e366-368.

12. Lerchenfeldt S, Mi M, Eng M. The utilization of peer feedback during collaborative learning in undergraduate medical education: a systematic review. BMC Med Educ. 2019; 19:321.

13. Hill E, Liuzzi F, Giles J. Peer-assisted learning from three perspectives: student, tutor and co-ordinator. Clin Teach. 2010; 7:244-246.

14. Furmedge DS, Iwata K, Gill D. Peer-assisted learning--beyond teaching: How can medical students contribute to the undergraduate curriculum? Med Teach. 2014; 36:812-817.

15. Freeman S, Eddy SL, McDonough M, Smith MK, Okoroafor N, Jordt H, et al. Active learning increases student performance in science, engineering, and mathematics. Proc Natl Acad Sci U S A. 2014;111:8410-5.

16. Carr SE, Brand G, Wei L, Wright H, Nicol P, Metcalfe H, et al. "Helping someone with a skill sharpens it in your own mind": a mixed method study exploring health professions students experiences of Peer Assisted Learning (PAL). BMC Med Educ. 2016;16:48

17. Bugaj TJ, Blohm M, Schmid C, Koehl N, Huber J, Huhn D, et al. Peerassisted learning (PAL): skills lab tutors' experiences and motivation. BMC Med Educ. 2019;19:353.

18. Boud D, Cohen R, Sampson JE: Peer Learning in Higher Education: Learning from and with Each Other, 1st edn. London: Routledge; 2001. https:// www.taylorfrancis.com/books/mono/10.4324/9781315042565/peerlearning-higher-education-davidboud-ruth-cohen-jane-university-techn ology-sampson.

19. Guraya SY, Abdalla ME. Determining the effectiveness of peer-assisted learning in medical education: A systematic review and meta-analysis. J Taibah Univ Med Sci. 2020; 15:177-184.

20. Rees EL, Quinn PJ, Davies B, Fotheringham V. How does peer teaching compare to faculty teaching? A systematic review and meta-analysis. Med Teach. 2016; 38:829-837.

21. Burgess A, McGregor D, Mellis C. Medical students as peer tutors: a systematic review. BMC Med Educ. 2014; 14:115.

22. Moher D, Liberati A, Tetzlaff J, Altman DG, Group P. Preferred reporting items for systematic reviews and meta-analyses: the PRISMA statement. BMJ. 2009; 339:b2535.

23. Topping KJ. Trends in Peer Learning. Educational Psychology. 2005; 25:631-645.

24. Higgins JP, Altman DG, Gøtzsche PC, Jüni P, Moher D, Oxman AD, et al. The Cochrane Collaboration's tool for assessing risk of bias in randomised trials. BMJ. 2011;343:d5928.

25. Deeks J, Higgins J, Altman DE. Chapter 10: Analysing data and undertaking meta-analyses. In: Higgins J, Thomas J, Chandler J, Cumpston M, Li T, Page M, Welch V, editors. In: Cochrane Handbook for Systematic Reviews of Interventions version 60 edn. 2019.

26. Higgins JP, Thompson SG. Quantifying heterogeneity in a meta-analysis. Stat Med. 2002; 21:1539-1558

27. Sterne JA, Sutton AJ, loannidis JP, Terrin N, Jones DR, Lau J, et al. Recommendations for examining and interpreting funnel plot asymmetry in meta-analyses of randomised controlled trials. BMJ. 2011;343:d4002.
28. Büscher R, Weber D, Büscher A, Hölscher M, Pohlhuis S, Groes B, et al. Evaluation of the peer teaching program at the University Children's Hospital Essen - a single center experience. GMS Z Med Ausbild. 2013;30:Doc25.

29. Cremerius C, Gradl-Dietsch G, Beeres FJP, Link B, Hitpaß L, Nebelung $\mathrm{S}$, et al. Team-based learning for teaching musculoskeletal ultrasound skills: a prospective randomised trial. Eur J Trauma Emerg Surg. 2021:47:1189-99.

30. Heckmann JG, Dütsch M, Rauch C, Lang C, Weih M, Schwab S. Effects of peer-assisted training during the neurology clerkship: a randomized controlled study. Eur J Neurol. 2008; 15:1365-1370.

31. Hudson JN, Tonkin AL. Clinical skills education: outcomes of relationships between junior medical students, senior peers and simulated patients. Med Educ. 2008; 42:901-908.

32. Kassab S, Abu-Hijleh MF, Al-Shboul Q, Hamdy H. Student-led tutorials in problem-based learning: educational outcomes and students' perceptions. Med Teach. 2005; 27:521-526.

33. Knobe M, Münker R, Sellei RM, Holschen M, Mooij SC, Schmidt-Rohlfing B, et al. Peer teaching: a randomised controlled trial using student-teachers to teach musculoskeletal ultrasound. Med Educ. 2010;44:148-55.

34. Kühl M, Wagner R, Bauder M, Fenik Y, Riessen R, Lammerding-Köppel M, et al. Student tutors for hands-on training in focused emergency echocardiography--a randomized controlled trial. BMC Med Educ. 2012;12:101.

35. Nomura O, Onishi H, Kato H. Medical students can teach communication skills - a mixed methods study of cross-year peer tutoring. BMC Med Educ. 2017; 17:103.

36. Rogers DA, Regehr G, Gelula M, Yeh KA, Howdieshell TR, Webb W. Peer teaching and computer-assisted learning: An effective combination for surgical skill training? J Surg Res. 2000; 92:53-55.

37. Shah I, Mahboob U, Shah S. Effectiveness Of Horizontal Peer-Assisted Learning In Physical Examination Performance. J Ayub Med Coll Abottabad. 2017; 29:559-565.

38. Steele DJ, Medder JD, Turner P. A comparison of learning outcomes and attitudes in student- versus faculty-led problem-based learning: an experimental study. Med Educ. 2000; 34:23-29.

39. Weyrich P, Celebi N, Schrauth M, Möltner A, Lammerding-Köppel M, Nikendei C. Peer-assisted versus faculty staff-led skills laboratory training: a randomised controlled trial. Med Educ. 2009; 43:113-120.

40. Widyahening IS, Findyartini A, Ranakusuma RW, Dewiasty E, Harimurti K. Evaluation of the role of near-peer teaching in critical appraisal skills learning: a randomized crossover trial. Int J Med Educ. 2019; 10:9-15.

41. Sterne JA, Gavaghan D, Egger M. Publication and related bias in metaanalysis: power of statistical tests and prevalence in the literature. J Clin Epidemiol. 2000; 53:1119-1129.

42. Ten Cate O, Durning S. Peer teaching in medical education: twelve reasons to move from theory to practice. Med Teach. 2007; 29:591-599.

43. Knobe M, Holschen M, Mooij SC, Sellei RM, Münker R, Antony P, et al. Knowledge transfer of spinal manipulation skills by student-teachers: a randomised controlled trial. Eur Spine J. 2012;21:992-8.

44. Kolb D: Experiential learning: Experience as the source of learning and development. Englewood Cliffs: Prentice-Hall; 1984.

45. Coffield F, Moseley D, Hall E. Learning styles and pedagogy in Post-16 learning - A systematic and critical review. In: LSCR reference. London: Learning Skills Research Centre; 2004.

46. Soriano RP, Blatt B, Coplit L, CichoskiKelly E, Kosowicz L, Newman L, et al. Teaching medical students how to teach: a national survey of students-as-teachers programs in U.S. medical schools. Acad Med. 2010:85:1725-31.

47. Glynn LG, MacFarlane A, Kelly M, Cantillon P, Murphy AW. Helping each other to learn--a process evaluation of peer assisted learning. BMC Med Educ. 2006;6:18.

48. Austria MJ, Baraki K, Doig AK. Collaborative learning using nursing student dyads in the clinical setting. Int J Nurs Educ Scholarsh. 2013;4:10.

49. Haidich AB. Meta-analysis in medical research. Hippokratia. 2010;14:29-37.

\section{Publisher's Note}

Springer Nature remains neutral with regard to jurisdictional claims in published maps and institutional affiliations. 